\title{
INFORMATICA FEMINALE: A PLACE FOR EDUCATIONAL EXPERIENCES
}

\author{
Veronika Oechtering and Karin Vosseberg \\ University of Bremen \\ Germany
}

\begin{abstract}
There is an ongoing discussion about the definition of informatics as a discipline and its foundations in education at an university level. Questions about the goals of studying and an informatics curriculum are formulated from different viewpoints. Women have special interests in changing the structure, culture and contents of the discipline. In May 1997, the project Informatica Feminale - Summer University for Women in Informatics started in the Department of Informatics at the University of Bremen (Germany). This project brings together female students and female professors from all German departments of informatics to work on new educational concepts in informatics. Three aspects are seen as focal points: new definitions of the informatics curriculum from women's viewpoints, the creation of testfields for new educational concepts (mainly in the context of summer courses), and further education of female university staff in informatics. In this paper we first give a brief description of the project. Then we outline some starting points of our curricular discussion and we explain the concept of the first Summer Courses for Women in Informatics to be held in Bremen in September 1998.
\end{abstract}

\section{INTRODUCTION}

The idea of the project Informatica Feminale 1 has its roots in three conceptual aspects of a 'liberal arts university': the definition of curricular bases, the education of students, and the promotion of research and teaching staff. All these aspects are inter-connected. They (re)construct the process of higher education and (re)define the institutional structures and culture of a 'university'.

During the last years, several studies outlined the male dominated settings of these processes and institutions (at least) in many European and North American countries (O'Barr 1994, Metz-Göckel/Steck 1997). Although this is relevant for all university subjects, the category of gender is deeply incorporated in technical disciplines. The marginal participation of female students in technical subjects can be seen as one indication. Its analysis leads to questions about the content and forms of education, about role models and mentoring systems, and about the players in the defining process of a discipline. For example in the relative new discipline 'informatics'- as a somewhat specific German counterpart to the Anglo-American 'computer science'(see Coy 1997) - several exclusion processes for women have been 
studied during the development of the discipline (Funken 1992, Schmitt 1993).

The growing importance of information and communication technology all over the world has raised a specific interest in gender-related questions concerning informatics. It has become obvious that there is no single strategy to break the cycle of discrimination. In several countries special programmes like 'Girls into Computing Days' have been established in secondary education, institutional promotion of girls and women through affirmative action programmes can be found in schools, universities and many working places, further technical education in 'women's only' groups has become important with a broader diffusion of computers in the 1980s and again with Internet services in the 1990s.

However not only women have to change their attitudes. Informatics (or computer science) itself has to create a new image, based on new disciplinary definitions and new educational shapings. Interests expressed by women need to be integrated. As only a few women are inside the discipline this requires the connection of women, to give them places, time and money for creating new ideas, to open the discourses for women outside the faculties. With our project Informatica Feminale - Summer University for Women in Informatics we try to make a first step into this direction. Many of our efforts result from former experiences within the specific context of the higher education system in Germany and the situation of women in informatics. Therefore we will briefly outline our context.

\subsection{Women in German informatics education}

In Germany, the number of women in academic studies of informatics has reached a dramatically low level (Oechtering/Behnke 1995, Schinzel 1997). The highest percentage of women studying informatics has been about $20 \%$ in 1983 in West Germany and nearly $50 \%$ in 1986 in East Germany. Due to the diffusion of personal computers into households and the introduction of the subject informatics at West German high schools, the female participation rate decreased to around $10 \%$ at the end of the 1980 s. Only three years after the reunion of East and West Germany, just 5\% of the beginners in academic informatics courses all over Germany were women, resulting in a female participation as a whole of $7.4 \%$ in 1993. A slightly increase to $9.7 \%$ in 1995 seems to be due to a rising participation of foreign students. This trend is similar in other European countries and the USA. (Grundy 1996, Richardson/Kavanagh 1997, Rasmussen 1997, Camp 1997).

Up to now, efforts to increase the participation of women in informatics in Germany have mainly concentrated on informing girls and women about engineering and natural sciences and motivating them to study these fields. Many educational pilot projects at national or local levels have been based upon the idea that the low participation of women in informatics is due to their assumed deficits in logical and technical competences and their lack of 
self-confidence. However several in-depth studies concerning the German high school system identified 'coeducation' and 'course choice systems' as important factors in keeping girls away from computing (summarised in Schinzel 1997). School experiments with single sex classes in science and informatics have been very successful. Recommendations for school curricula have been edited, but the realisation process is difficult as the education system belongs to the authority of the German Länder. Another very critical point is the marginal relevance of gender aspects in the university education of school teachers for technical subjects.

Investigations about the declining rate of women in academic informatics and about the reasons why so many women give up these studies reveal similar causes. The main obstacles for women have been identified in the culture of the discipline which seems to be dominated by a techno-centred image and by the habits and working styles of so-called 'computer freaks'. Further obstacles are caused by the divergence of (socially constructed) stereotypes of technical experts and of femininity (Roloff 1989, Schmitt 1993, Freyer 1993). Previous measures for women's empowerment in informatics do not sufficiently consider the influence of such structural and cultural conditions on the female participation in the discipline. Up to now measures for increasing women's participation in informatics aim especially at improving their access to computers. It has been neglected to also promote the retention of women in high qualified professions like the IT professions. Recent findings show, for example, that theoretical computer science for women often serves as a sort of access path to informatics in the beginning of their studies or of their academic careers (Erb 1996 and Erb 1997).

\subsection{Encouraging aspects for new ways of engagement}

As mentioned above several investigations in the broader research of women's studies have been dedicated especially to the subject 'women and informatics'. Thus several specific problems in the field have already been well analysed, and the results are useful for the further empowerment of women.

Compared to other science and engineering professions, the situation in German informatics is in a way exceptional: there exists a certain potential of women at all levels of qualification. On the one hand, these pioneering women are important as role models for female careers in computing. On the other hand, in Germany a relative high proportion of them is organised in the Working Group 'Women's Work and Informatics' (Fachausschuß Frauenarbeit und Informatik) of the German Society for Informatics (Gesellschaft für Informatik - GI). This group is very engaged in promoting women's interests in informatics at scientific and political levels. At several universities, there exist local groups of female computer scientists who organise single sex tutorials at informatics departments or promote gender studies in informatics. 
Apart from the activities of female computer scientists, some other conditions create an atmosphere of change in informatics. There are several discussions about guidelines and paradigms for this discipline (Coy et al. 1992). Paradigm shifts are discussed which seem to become necessary because of technological developments and because of arising social requests concerning new technologies. Furthermore, discussions at German universities on evaluating and improving education (not only) in informatics have created an open atmosphere for testing new forms of studying and teaching.

The University of Bremen has taken part in the discussions on women's studies and women's empowerment in informatics from the very beginning (Schelhowe/Vosseberg 1991). In 1989, the first German conference on women and computing 'Frauenwelt - Computerräume' was organised in Bremen by the GI-Working Group (Schelhowe 1989). The first professorship in women's studies in informatics has recently been established at the Informatics Department of Bremen University. Motivated by all these achievements the idea of a summer university for women in informatics was born.

\section{SUMMER UNIVERSITY FOR WOMEN IN INFORMATICS}

In 1994, a concept for a pilot project Informatica Feminale was submitted to the Commission of the Federal Government and the Länder for Educational Planning and Research (Bund-Länder-Kommission für Bildungsplanung und Forschungsförderung - BLK). The proposal received positive reports from referees, but the decision of the commission was pending for two years because of a severe lack of money. Finally a smaller approach to our project has been realised with funding by the Land Bremen and the University of Bremen $^{2}$.

\subsection{Objectives of Informatica Feminale}

In the last years, different projects have been established to increase the number of female students. But all these measurements have had no visible success until today. In our opinion it is very difficult to motivate girls to study informatics without changing the content and image of informatics.

Therefore our goal is to bring together female students and female professors or lecturers from all German departments of informatics to work on new educational concepts in informatics and to give them the opportunity to try new forms of teaching and learning in an exemplary manner. Three aspects are seen as focal points: new definitions of informatics curricula from women's viewpoints, the creation of test-fields for new educational 
concepts mainly in the context of summer courses, and the further education of female university staff in informatics.

Informatica Feminale shall be a place where new methods are analysed especially with regard to their potential

- for motivating women to study and especially to stay in informatics;

- for motivating them to participate in discourses about curricula and didactic development;

- $\quad$ for motivating them to pursue an academic career;

- for motivating them to choose permanent positions in a field of technology.

We will now outline the three aspects of the project in more detail.

\subsection{Combining three aspects in a concept}

Novel measures for the equality of women must not stop at the question of how to teach the subject for women. The Informatica Feminale should not only be a repetition of special 'women-only-tutorials'. On the contrary, women are interested in changing the culture of studying in the sense of a changed atmosphere and changed priorities in the organisation of research. Therefore we strive for a combination of informatics summer courses for women, a curricular discussion among women and the further education of female computer scientists. All these three elements of the project should give women the power to take more influence at different levels of the scientific and academic culture.

\subsubsection{Summer courses for women}

The nucleus of the project consists of a specific offer of seminars and classes in informatics at a university level. The two-week courses are designed by female professors, by female scientists and women from practice. In reaction to a widely distributed 'Call for Lectures' all interested women can send a teaching concept.

Potential participants are, first of all, female students of informatics in universities or polytechnics, but also students of other related disciplines or students of school teaching in informatics. The summer courses may also serve for women to refresh their studies, especially to refresh relevant professional knowledge, or to qualify them for a professional re-entrance, for example after an interval of child care and education. The summer university is directed to participants all over Germany and it is open for international participants.

Topics cover the whole spectrum of informatics, that means the domains of theoretical, practical, technical and applied informatics, and they refer to the existing German curriculum recommendations which have been published by the 'Gesellschaftfür Informatik'. The results of current curriculum 
discussions are taken into account as well as experiences with curricula of specific universities or polytechnics. The summer courses are a place where new forms of teaching and learning in informatics can be tried out in an exemplary manner.

A variety of offers is supposed to be realised:

- fundamental and special courses;

- $\quad$ practical courses;

- $\quad$ planning games;

- excursions;

- $\quad$ presentations of special (industrial) applications;

- workshops;

- plenary sessions, lectures and panel discussions about actual subjects.

We try to arrange that the completion of summer courses will be accepted in the informatics departments of German universities. In this way students could complete parts of their studies by visiting the summer university.

Accompanying the summer courses there are opportunities for discussions and exchange among lecturers and between lecturers and students about curricula matters, didactics, and methods of teaching, but also about individual conditions of living, learning, and working, which will be useful to help students finding their own professional orientations (Pfleeger/Mertz 1995).

\subsubsection{Curricular discussions among women}

In preparation for the summer courses, workshops are organised to reflect the existing informatics curricula and to develop potential changes which take into account the special interests of women. The workshops are especially intended to lecturers of the summer courses, but also to didactic experts and other interested female computer scientists. In these workshops the thematic spectrum of the summer classes are discussed, as well as feminist and didactic topics and methods.

\subsubsection{Further education for female scientists}

Feminist studies about the declining rate of women in computer science have come to the conclusion that one of the main obstacles for women in technical disciplines lies in the structural and informal conditions of scientific and academic culture. It is planned to install special assistance for female scientists at different levels of career where such obstacles are investigated and made transparent. Such assistance will consist of didactic courses or in the mediation of knowledge about structural conditions in scientific and academic fields, for example how to establish external cooperations and networks in sciences. 


\section{PRELIMINARY STUDIES}

In a small pre-project in 1995, some insights could be received into the interest among female computer scientists towards the project Informatica Feminale. Ingrid Rügge and Veronika Oechtering inquired among female informatics professors in Germany, and they organised a workshop 'Changing the Informatics curricula - a discussion among women' ('Informatik-Curricula im Wandel -Eine Diskussion unter Frauen') in December 1995 in Bremen. Both the inquiry and the workshop have shown that there is great interest among women in informatics at all points of their university career (Rügge 1997). It has also become evident that there is a great potential of competent lecturers for the summer courses.

The participants of the workshop discussed the organisation of the summer courses and its contents in a controversial way. Some of them wished a very strong orientation on existing German curriculum recommendations. For them it is necessary that students get the completion of the summer courses accepted in their own informatics departments. Other participants require the integration of feminist discussions into the summer courses. The Informatica Feminale should not become a stopgap for existing informatics departments. It is important to find the golden mean between these contrary positions in order not to split the women's power.

Another discussion point was the experimentation with different forms of summer course. It was the unanimous view that form and content of a course depend on each other. Therefore great engagement of the lecturers is required. The lecturers must be willing to reflect the form and content of their courses. An evaluation of the summer courses should take place from a didactic and a feminist viewpoint.

Experiences in other projects have shown that special strategies must be developed for motivating female students to take part in the Informatica Feminale. Single-sex tutorials at universities have a very low acceptance if they do not fulfil specific pre-conditions. The female students often feel that they do not need some special treatments. But they are very interested in offers which refer to actual subjects and can be seen as an additional bonus. This means that Informatica Feminale needs to take up actual informatics discussions in the summer courses.

At least the participants of the workshop were very interested in further education and they collected some topics they want to be engaged in: project and time management, didactic courses, supervision, education as entertainment, self-knowledge and methods of relaxation.

The results of these discussions influenced the preparations of the first curricular workshop in the project Informatica Feminale which took place in December 1997. 


\section{CURRICULAR DISCUSSIONS OF THE FIRST SUMMER COURSES}

Under the motto 'Informatics education: between scientific findings and acquisition of professional skills?' ('DasInformatikstudium: Zwischen wissenschaftlicher Erkenntnis und Erwerb vonBerufsfähigkeiten?') the participants of this workshop discussed their own anticipations and interests in the Informatica Feminale. Proceeding from the general discussion about German informatics curricula, a first concrete concept has been developed for the summer courses in September 1998. For better understanding we will first summarise the general discussion and then outline the background of the forthcoming summer courses.

Where is the place of informatics in the scientific landscape? What are the foundations of education? Which goals are useful, suitable and reachable? Who is defining the goals? How can we meet the goals? All these questions are important, and not only for women. And by the way, it is a pleasure to observe that there is a motion in the scientific community to look at the roots of informatics from different viewpoints.

\subsection{Discourses of defining informatics as a scientific discipline}

At the end of the 1980s and the beginning of the 1990s well-known computer scientists like Dijkstra and Parnas have initiated a new selfunderstanding discussion of computer science. What is computer science: 'modern' mathematics with a concentration on formal methods (Dijkstra 1989), or an engineering or technical science which develops technical artefacts (Parnas 1990)? In Germany the view on informatics as a scientific discipline is extended in the directions of human and social sciences. This is owed especially to the discourse about a 'Theory of Informatics' ('Theorie der Informatik') (Coy et al. 1992). Up to now it is an open question how to integrate these discussions into extending the foundations of informatics knowledge, models and methods.

In Germany, informatics as a university study has its beginnings in mathematics and engineering sciences such as electrical engineering. This is based on the origin of the first professors relating to their own education and on traditional academic structures (departments, faculties, scientific societies, publication organs, conferences, etc.). The development of informatics as a technical science was, and remains up to now, an interrelation between differentiation and cooperation with the named studies. But informatics orients itself also on traditions of human and social sciences. Looking at the processes of formation at different German informatics departments, they reflect the specific atmosphere of the university, which is responsible for its characteristic directions (see also Coy 1997). 


\subsection{Using the quarrel in finding a new image of technical sciences}

It seems to us that the vital point in the discourse is not the quarrel in defining separated disciplines or directions, nor in choosing the 'right' method. The goal must be to integrate basic values of human society in all steps of scientific findings, by using informatics knowledge and informatics working competences. All technical sciences, especially informatics, are more and more in a paradox situation. On the one hand, male and female technical engineers (computer scientists) necessarily are directly bound up to their technology, they are crucial responsible for development and design of technology. They are formed in their thoughts and behaviours by the base principles of technology, they transport the unbalanced norms of rational acting which are influenced by the actual educational and scientific system, and this beams out even on their (male) personality as a whole. On the other hand, they are living in a society which is on the way to an information society. In this society the economic, social or ecological conflicts of technological development become more and more evident. Meanwhile technology is found everywhere, and the technical engineers are asked for problem solutions while they are substantially responsible for the problems. On the one hand, technical engineers are at the point where they could become directly active but, on the other hand, they are involved in the pressure of technical practicability, economical justifiableness and social/personal dependencies.

Despite all efforts of educational reforms these contradictions are not discussed either in school education or at university level. This deficit becomes evident in the practice of technical engineers. In this context the call for some key qualifications becomes louder. From the viewpoint of industrial managers, new qualities like working in a team, organisational competence, flexibility, openness, independence, responsibility, social competence, etc. are demanded (for example in VDE 1994 and VDI 1995).

A modern informatics education must find a good balance between the different scientific influences and the requirements of industry (Schelhowe 1997). It is not necessary to follow the claim of Anne Mahn (Mahn 1997) for finishing the quarrel between searching for scientific findings and the acquisition of professional skills in favour of professional skills. In our opinion there is no contradiction. Quite the contrary, scientific findings only make sense if male and female scientists know these relations. Therefore in the curricular discussion we should not only bear the requirements of industry in mind but also make the requirements of a changed science perceptible. From women's perspectives, the self-understanding discussion must be under way to bring in new positions with respect to male and female interests. 


\subsection{Some comments on a different education from a women's perspective}

To get a new quality in the technical education at university level some curricular and methodological changes are necessary. In our opinion a structuring of an informatics study in content-independent separated courses was not successful in meeting all the described requirements. Women demand again and again to bring out the references in the content. Is a subject-oriented approach another way for structuring an informatics curriculum? Subjects like networking, limits of informatics, quality assurance, the future of new media, or something similar, can be a frame to point out the relations between the different aspects of theoretical, technical, practical and applied informatics. It is not possible to give a global answer on the relation between content and applied methods in a complex field like, for example, software development. Therefore it is necessary to teach various methods: discursive methods of human and social sciences should be learned as well as formal and engineering methods. Interests in scientific findings should not be played off against working competencies. These are a necessary behaviour which is important for men and women to be trained in.

In several informatics departments we can observe a movement in the direction of project-oriented studies, but only a few departments like Bremen, Dortmund or the new department of software engineering in Stuttgart make projects obligatory for all students in their curriculum. On the one hand, subject-oriented projects give the framework to offer basic knowledge in informatics and to discuss actual research aspects. Projects are also a place to get experiences with different methods. On the other hand, students can learn working competences in a relative secure way. Despite the different directions of polytechnics and universities, projects build the framework to accentuate industrial cooperation in polytechnic education and to preserve the margin of scientific findings at the universities. From a women's perspective it is necessary to follow up the question whether project-oriented studies really meet the interests of women, and which requirements must be fulfilled (compare the corresponding reforms at universities in Sweden (Salminen-Karlsson 1997)). Project-oriented studies, that is to say, require a great engagement of all participants. This is shown by some experiences with the project-oriented study in Bremen (Vosseberg/Spillner 1993).

\subsection{Background of the summer courses}

For the first time, the summer course took place at the University of Bremen from September 21st to October 2nd, 1998. The programme covered a broad spectrum of informatics topics. Following the results of the first curriculum workshop a Call for Lectures was published and widely distributed in January 1998. The response to the call was overwhelming. In March and April offers from 52 professors, lecturers, researchers and practitioners in Informatics were accepted and put together into a two-weeks programme 
with lessons, practical courses, seminars, workshops, projects and lectures from diverse areas of Informatics. Lecturers from Austria, Denmark, Great Britain, the Netherlands and USA were invited. The final programme is available as a booklet and from our web-pages (http://www.informatik. uni-bremen.de/grp/informatica feminale/Sommerstudium).

Our intention has not been to develop a new list of important informatics courses which are especially interesting for women. On the contrary we want to make experiments with new ways of describing an informatics curriculum. For the curriculum of the summer courses we have chosen a subject-oriented approach. The courses will not be arranged in the classical categories: theoretical, technical, practical and applied informatics. We have grouped the courses on the basis of actual subjects in the informatics discussion. Under each subject, theoretical, technical, practical and applied aspects should be discussed in one or more courses. With this we hope to break down the 'firewalls' between the classical categories of the informatics curriculum. For the first summer courses in September 1998 we concentrated on three subjects: Information networks, Software development as a process and Interaction and media.

In order not to get new 'firewalls' we have also combined all these actual subjects in a special series of lectures. This series has invited talks on common aspects of the different topics and additionally we will present women who introduce feminist discussions. Besides the courses arranged under these actual subjects we have especially organised for undergraduate students several basic courses such as programming courses in a modern programming language, system administration or Internet.

\subsubsection{Information networks}

A common argument says that information networks, especially the Internet, show a communicative character which is well adapted to women's needs. So far the Internet has been a very fluid technology which can be shaped to a certain extent (Spender 1995). Whether and how it should be shaped to support women and their particular needs and interests is an open question.

The goal of the subject Information networks is to address theoretical and technical aspects of these discussions. The focus will be on the technical basis, such as protocols of computer networks or languages, as well as on interdisciplinary discussions about forms of usage, applications, questions of privacy and feminist approaches.

\subsubsection{Software development as a process}

Software development is not a task for one man sitting alone in a closed room and working out a problem solution for himself. The characteristic of 
software development is cooperation and communication of all persons involved in the software development process: clients, developer, users, etc. Girls and young women are often not interested in studying informatics because they do not like sitting behind a machine the whole day, they like to work with other people (Rasmussen 1997). One goal of the summer courses in the subject Software development as a process is to change the common image of a lonely hacker.

The focus of this subject will be on the models and methods of software development along the software life cycle. Besides formal and technical models and methods to develop software architecture, aspects of project and quality management get their place. But the nucleus of the discussions should be how to support the cooperation and communication of all participants involved in the software development process.

\subsubsection{Interaction and media}

Text-based communication in virtual environments is characterised by an absence of the physical body. In fact, the possibility to escape from one's own body seems to be one of the main motivational factors to participate in virtual spaces. The gendered body theoretically does not play an important role any more, if the decision about gender is a free choice in the world of the net. But bodily signs are not forgotten in the net. Gender is done by men and women - and it is fundamentally interactive (Panel 1997).

What are the technical signs of gendered interaction? Which bodily representations constitute gendered actions and orders in virtual reality? These and further questions are central to the subject Interaction and media in the summer courses. Theoretical, practical and technical problems of visualisation or computer graphics will be taught and discussed together with philosophical questions.

\section{CONCLUSION}

At this time the analysis of gender-based constructions inside informatics has only started with some first steps. Too often the theme is discussed in a very general and common way. Women who are engaged in the effects of gender in information technology have to work in that field in addition to another informatics theme. Even if the importance of women's views on information technology is recognised, the need for women's own test-fields in constructing new curricula contents and methods of reflection are not yet well accepted. Therefore an aim of our project is to open ways for better understanding and support for gender-based research and actions in informatics. Especially with the summer courses we want to open a new place to come together and create new perspectives in that field. 


\subsection{Supplementary remark}

As this text is published, two years of very successful project work has already been done. Especially we can look back on two summer courses, one in 1998 with more than 120 students, and another in 1999 with more than 200 students. Participants came from 60 universities all over Germany and from Austria. Evaluations have already given some insight into the situation of female students in informatics, and first suggestions as to how to change existing curricular could be developed (more information can be found in recent papers of the authors, see References).

We are interested in further, especially international contacts. Interested persons who would like to participate in the following summer courses in 2000 as lecturers or as students, or who have further suggestions and ideas, are requested to contact the authors of this paper.

\section{NOTES}

1 The project is led by Prof. Dr. Hans-Jörg Kreowski. The project term is May 1997 May 2000.

2 Funding is realised in a programme called 'Hochschulsonderprogramm (HSP) III'- a specific national programme for universities and polytechnics in all Länder passed in 1996. The amount of money and specific area of use dedicated to women's promotion is partly fixed in HSP III.

\section{REFERENCES}

Camp, T. (1997) The incredible shrinking pipeline. Communications of the ACM 40(10) 103110.

Coy, W. (1997) Defining discipline.

http://waste.informatik.huberlin.de/I+G/Coy/Coy_Defining_Discipline.html.

Coy, W. et al. (eds.) (1992) Sichtweisen der informatik. Vieweg, Braunschweig.

Dijkstra, E. W.(1989) On the cruelty of really teaching computing science. Communications of the ACM 32 1398-1404.

Erb, U. (1996) Frauenperspektiven auf die Informatik.Informatikerinnen im Spannungsfeld zwischen Distanz und Nähe derTechnik. Westfälisches Dampfboot, Münster.

Erb, U. (1997) Exploring the excluded. a feminist approach to opening new perspectives in computer science. In A. F. Grundy et al. (eds.) Women, Work, and Computerization. Proceedings of the 6th International IFIP-Conference, Bonn. Springer, Berlin, pp. 201-207.

Freyer, C. (1993) Alles nur Bluff? - Programmier en als ein Bestandteil der Fachkultur Informatik. In Ch. Funken, B. Schinzel (eds.) Frauen in Mathematik und Informatik. Tagungsbericht Dagstuhl, pp. 60-64.

Funken, C. (1992) Wissenschaftlerinnen in der Informatik. In: G. Müller u.a. (eds.):Bericht des Instituts für Informatik und Gesellschaft der Universität Freiburg, No. 6-92, pp. 3-24.

Grundy, F. (1996) Women and computers. Intellect, Exeter. 
Mahn, A. (1997) Informatische Berufsfähigkeiten. Informatik Spektrum 20(2) 88-94.

Mahn, A. and Brauer, W. (1997) Schwerpunktheft zum Thema 'Informatik: Selbstverständnis - Anwendungs-bezüge- Curricula'. Informatik Spektrum 20(2).

Metz-Göckel, S. and Steck, F. (eds.) (1997) Frauenuniversitäten: Ein Reform-Projekt im internationalen Vergleich. Leske+Buderich.

O'Barr, J. F. (1994) Feminism in Action. The University of North Carolina Press, Chapel Hill.

Oechtering, V. and Behnke, R. (1995) Situations and advancement measures in Germany. Special Issue on 'Women in Computing'. Communications of the ACM 38(1) 75-82.

Oechtering, V. and Vosseberg, K.(1999) Changing the university education of computer science. In: IEEE (ed.) Women and technology: historical, societal, and professional perspectives. Proceedings of the 1999 IEEE International Symposium onTechnology and Society (ISTAS 99), New Brunswick (N.J.), pp.73-79.

Panel (1997) Bodily functions in cyberspace.Transcription of a panel at the 6th International IFIP-Conference, Bonn. http://duplox.wz-berlin.de/docs/panel/

Parnas, D. L. (1990) Education for computing professionals.IEEE Computer 23(1) 17-22.

Pfleeger, S. L. and Mertz, N. (1995) Executive mentoring: what makes it work? Communications of the ACM 38(1) 63-73.

Rasmussen, B. (1997) Girls and computer science: 'It's not me. I'm not interested in sitting behind a machine all day'. In A. F.Grundy et al. (eds.) Women, work, and computerization. Proceedings of the 6th International IFIP-Conference, Bonn. Springer, Berlin, pp.379-386.

Richardson, I. and Kavanagh, I. (1997) Positive action: promotingtechnology and science through female role model. In R. Lander and A. Adam (eds.) Women in computing. Intellect, Exeter pp. 173-180.

Roloff, C. (1989) Von der Schmiegsamkeit zur Einmischung. Professionalisierung der Chemikerinnen und Informatikerinnen.. Centaurus, Pfaffenweiler.

Rügge, I. (1997) Hätten Sie Interesse? Frauenarbeit und Informatik, no. 15, pp. 63-67.

Salminen-Karlsson, M. (1997) Why do they never talk about the girls? In: R. Lander and A.Adam (eds.) Women in computing. Intellect, Exeter, pp. 160-172.

Schelhowe, H. (1997) Informatik - Innovative Forschung und Lehre fürFrauen. In: S. MetzGöckel, F. Steck (eds) Frauenuniversitäten: Ein Reform-Projekt im internationalen Vergleich. Leske+Buderich, Opladen.

Schelhowe, H. and Vosseberg:, K. (1991) Aspects of women's research in computer science. In: V. Erikson et al. (eds.) Women, work, and computerization. Proceedings of the 4th International IFIP Conference, Helsinki. Elsevier, Amsterdam, pp.379-386.

Schelhowe, H. (ed.) (1989) Frauenwelt - Computerräume. Springer, Heidelberg.

Schinzel, B. (1997) Why has female participation in German informatics decreased? In: A. F. Grundy et al. (eds.) Women, work, and computerization. Proceedings of the 6th International IFIP Conference, Bonn. Springer, Berlin, pp. 365-378.

Schmitt, B. (1993) NeueWege - alte Barrieren. Beteiligungschancen von Frauen in der Informatik. Ed. Sigma, Berlin. 
Spender, D. (1995) Nattering on the net. women, power and cyberspace. Spinifex Press, Melbourne.

VDE-Verband DeutscherElektrotechniker (1994) Auswirkungen des Strukturwandels der Elektroindustrie aufdie Ingenieurausbildung. Frankfurt/Main.

VDI-Verein Deutscher Ingenieure (1995) Ingenieur-Ausbildung im Umbruch. Empfehlung des VDI für eine zukunftsorientierte Ingenieurqualifikation. Düsseldorf.

Vosseberg, K. and Oechtering, V. (1999a) Sommeruniversität für Frauenals Weg der Studienreform in technischen Fächern. To be published in: Proceeding of the Symposium 'Frauen in Wissenschaft und Forschung -Strategien der Frauenförderung zwischen Institution und Autonomie'. Heidelberger Institut für interdisziplinäre Frauenforschung, Stuttgart, 12/13 July 1999.

Vosseberg, K. and Oechtering, V. (1999b) Changing the male university culture in informatics: the project Informatica Feminale. To be published in Proceedings of the 7th International Conference on Women's Worlds (WW99), Tromsø, Norway, June 1999.

Vosseberg, K. and Spillner, A. (1993) Das KOKS-Projekt - das Bremer Projektstudium am Beispiel vorgestellt. In: J. Raasch et al. (eds.) Software Engineering im Unterricht der Hochschulen SEUH'93. Teubner, Stuttgart, pp.83-93. 